\title{
Attitudes of Communication Sciences and Disorders Students at Jordan University of Science and Technology toward Stuttering and People Who Stutter
}

\author{
Khalid G. Al-Shdifat ${ }^{a}$, Mikhled Maayah ${ }^{a}$, Robert Mayo ${ }^{b}$, Kenneth St. Louis \\ ${ }^{a}$ Department of Rehabilitation Sciences, Jordan University of Science and Technology, Irbid, Jordan \\ ${ }^{b}$ Department of Communication Sciences and Disorders, The University of North Carolina Greensboro, Greensboro, NC, USA \\ ${ }^{c}$ Department of Speech Pathology and Audiology, West Virginia University, Morgantown, WV, USA
}

Correspondence: Khalid G. Al-Shdifat, PhD Department of Rehabilitation Sciences, Jordan University of Science and Technology, P.O. Box 3030, Irbid 22110, Jordan

Tel: $+962-779098548$

Fax: $+962-27095123$

E-mail: kgalshdifat@just.edu.jo

Received: June 20, 2018

Revised: October 6, 2018

Accepted: November 25, 2018

The authors would like to acknowledge Jordan University of Science and Technology for their cooperation in allowing this study on campus.
Objectives: The current study explored the attitudes of 1st, 2nd, 3rd, and 4th year students in Communication Sciences and Disorders (CSD) at Jordan University of Science and Technology (JUST) toward stuttering and people who stutter (PWS). Methods: All students in the CSD program from each year level at JUST were invited to participate in the current study. A translated Arabic version of the Public Opinion Survey of Human Attributes-Stuttering (POSHA-S), a standard instrument, was used to compare stuttering attitudes from the four classes and also to compare them to attitudes of similar students and the general population from different countries on the POSHA-S database. Results: Data collected from the CSD students at JUST did not reflect any significant change in students' overall attitudes toward stuttering as they progressed from the 1st through the 4th year. However, they exhibited more positive attitudes than the public in Jordan. Compared to the POSHA$S$ database, Jordanian attitudes were somewhat less positive than most SLP students sampled in other regions. Conclusion: The current study revealed that students of CSD in Jordan hold less positive attitudes toward stuttering and PWS compared to people from other countries in the same region. Findings are discussed relevant to the literature on attitudes toward stuttering and PWS.

Keywords: Stuttering, Attitudes, CSD students, Jordan University of Science and Technology, POSHA-S, Arabic
A large and growing body of research has documented that the nonstuttering majority holds negative attitudes and stereotypes toward people who stutter (PWS) (e.g., Al-Khaledi, Lincoln, McCabe, Packman, \& Alshatti, 2009; Alshdifat, Mayo, \& St. Louis, 2013; Bellegarde, Mayo, St. Louis, \& Mayo, 2016; Elsiddig, Haynes, Atwood, \& St. Louis, 2013; Flynn \& St. Louis, 2011; Ip, St. Louis, Myers, \& Xue, 2012; Özdemir, St. Louis, \& Topbas, 2011a, 2011b; Reichel \& St. Louis, 2004, 2007; Ruscello, Lass, French, \& Channel, 1989; St. Louis, 2012; St. Louis, Andrade, Georgieva, \& Troudt,
2005; St. Louis \& Lass, 1981; Turnbaugh, Guitar, \& Hoffman, 1979; Van Borsel, Verniers, \& Bouvry, 1999; Woods \& Williams, 1976). Moreover, there has been a growing interest recently in examining the public attitudes towards stuttering in different cultures and countries (St. Louis, 2015; St. Louis et al., 2005; St. Louis \& Roberts, 2010), which highlights the need for a standard and a valid instrument to measure attitudes of the public toward stuttering (Flynn \& St. Louis, 2011; St. Louis et al., 2005).

Even though different instruments have been developed for the 
purpose of measuring attitudes toward stuttering (Ham, 1990; Van Borsel et al., 1999; Woods \& Williams, 1976), they fail to capture differences related to culture and experience with stuttering. Such inconsistencies among different tools pose a great threat to their validity (St. Louis, Przepiorka, et al., 2014). The POSHA-S on the other hand was designed to be used all over the world (St. Louis et al., 2005; St. Louis, 2011, 2012; St. Louis \& Roberts, 2010). Moreover, it has been shown to be a reliable and valid instrument and has been translated to 28 different languages, including Arabic, and has been used in 42 countries (circa, August 2016). The POSHA-S has been used regionally in the Middle East in Turkey (Özdemir et al., 2011a, 2011b), Kuwait (Abdalla \& Al-Saddah, 2009; Al-Khaledi et al., 2009; Abdalla \& St. Louis, 2012; St. Louis, Abdalla, Burgess, \& Kuhn, 2013), Jordan (Alshdifat et al., 2013), Saudi Arabia (F. Abdullah, personal communication, January 8, 2014), Sudan (Elsiddig et al., 2013), Syria (Mallah, 2011), and with Arab immigrants in Sweden (Nilsson \& Wetterling, 2013). In addition, research has looked at the attitudes of practicing SLPs to explore whether they hold negative attitudes toward stuttering and PWS similar to the public, and to find which factors contribute most to their negative attitudes (Maviş, St. Louis, Özdemir, \& Toğram, 2013; Yairi \& Williams, 1970). In general, CSD students as well as practicing SLPs are reported to hold negative impressions of people who stutter, similar to the general public (Koutsodimitropoulos, Buultjens, St. Louis, \& Monfries, 2016; Reichel \& St. Louis, 2004; Ruscello et al., 1989; St. Louis \& Lass, 1981; Turnbaugh et al., 1979).

St. Louis, Przepiorka, et al. (2014) explored the attitudes of SLP undergraduate, graduate, and non-SLP students in the USA and compared them to the attitudes of undergraduate SLP and nonSLP students in Poland. They reported that undergraduate and graduate SLPs had more positive attitudes toward people who stutter than control groups; they called this effect a 'halo effect' which they attributed partially to students being in a communication disorders field of study. Their results were in accordance with the results of Dhingra and Bhnatnagar (2006) who explored the attitudes of undergraduate and graduate speech-language pathology students toward people with disability. It is worth noting that previous research on the attitudes of Arabic speaking subjects toward stuttering and PWS were conducted on the public (Al-Khaledi et al., 2009; Alshdifat et al., 2013; Elsiddig et al., 2013; F. Abdullah, personal communication, January 8, 2013), pre-service and in- service school teachers (Abdalla \& Al-Saddah, 2009; Abdalla \& St. Louis, 2012, 2014) and teachers (Irani, Abdalla, \& Gabel, 2012), non-SLP students (St. Louis et al., 2013), and public Arab immigrants (Nilsson \& Wetterling, 2013). Although the aforementioned studies were conducted on people who speak Arabic, they revealed differences in attitudes toward PWS. In addition, to our knowledge there are no studies that have explored the attitudes of Arabic speaking people in the field of CSD toward stuttering and PWS. Therefore, the current study explored the attitudes of 1st, 2nd, 3rd, and 4th year undergraduate CSD students at JUST. This information would allow for comparison across students at different levels in the CSD program. It would also make it possible to examine if students' attitudes toward stuttering and PWS might be influenced simply by being in their chosen field of study (i.e., a 'halo effect'), namely CSD for the following reasons: First, 1st year students are minimally exposed to knowledge about specific communication disorders (e.g., stuttering). They take general requirement and introductory level courses to CSD (e.g., introduction to audiology and speech pathology). Second, as students proceed in their program, they are exposed to more in depth knowledge about the types of communication disorders. Third, students take the fluency disorders course in the second semester of the 3rd year of their program of study. Fourth, students in the undergraduate program of CSD start their clinical training in their 3rd year of the program in which they are exposed to subjects with different communication disorders. Thus, the purpose of the current study was to explore the attitudes of 1st, 2nd, 3rd, and 4th year undergraduate CSD students at JUST toward stuttering and PWS. Moreover, the study sought to compare their attitudes on the POSHA-S database to the attitudes of the public in Jordan and to people from other Arabic speaking countries. It also compared the attitudes of 1st through 4th year CSD students at JUST to one another toward stuttering and PWS to check if their attitudes changed as they progressed in the program.

\section{METHODS}

\section{Participants}

Undergraduate 1st, 2nd, 3rd, and 4th year students in the CSD 
program at JUST were recruited for the current study. Students were informed that participation was voluntary and no one would be penalized for opting not to participate in the study. The students were provided with consent forms to sign stating their willingness to participate in the study. The number of undergraduate students invited to fill out the POSHA-S was 179; they were 46 students from 1st year, 47 students from 2nd and 3rd years each, and 39 students from 4 th year. All the students recruited for the study were from JUST. Permission to conduct the study was obtained from JUST institutional research board (IRB). With regard to course work, 1 st and 2nd year students take pre-requisite courses and introductory level courses to CSD. It is in their 3rd year of study when they begin taking courses focusing on specific disorders and start their clinical practicum courses. They usually take 4 clinical training courses until they graduate from the program. Moreover, 3rd year students take clinical practicum course 1 during the 1st semester, which mainly focuses on speech sound disorders (SSDs). They start seeing clients with language and fluency disorders when they take their clinical practicum course 2 in the 2 nd semester of their 3rd year; however, they do not see many cases with fluency disorders since it is their 2 nd practicum course and since they take it with the fluency course simultaneously.

\section{Instrument}

The Arabic version of the POSHA-S was used in data collection in the current study. The POSHA-S is a standard instrument that was developed over a period of 12 years to reliably measure public attitudes around the world which also allowed the creation of a database that can allow comparisons of the public attitudes toward stuttering and PWS (St. Louis, 2012). The POSHA-S is comprised of three sections. The first section is related to gathering demographic data from participants (e.g., age, sex, marital status, occupation, etc.). The second is a general section that compares stuttering to four human attributes (i.e., intelligent, left handed, obese, and mentally ill). The third section of the POSHA-S asks in depth questions on stuttering. The POSHA-S asks about respondents' beliefs and reactions to stuttering and the cause of stuttering. It also asks how respondents would behave or feel when they interact with a person who stutters, and the person who they should turn to in order to help a person who stutters. Moreover, it asks them how concerned they might be if someone they knew stuttered (e.g., significant others) and their beliefs about the life potential of PWS. The POSHA-S takes about 10 minutes (St. Louis, Przepiorka, et al., 2014) which is not taxing to fill out. Results from different studies across the world are entered into the POSHA-S database to allow for comparison of the attitudes of the samples on the database (St. Louis, 2012).

\section{Procedure}

The students were surveyed in the 2nd semester of the 2015 academic year. Students were given the survey either by the researcher or an assistant, and were asked to fill them out and hand them back once they were finished filling them out.

\section{Analysis}

The data collected using the POSHA-S was analyzed on the POSHA-S database and the respondents' overall stuttering rating was compared to the attitudes of respondents from 23 countries who speak 15 languages. Independent sample $t$-tests were carried out for group comparisons. Significance level for group comparisons was set at a $p$-value of $\leq .00417$.

\section{RESULTS}

The demographic data for the four groups of students are presented in Table 1. As can be seen from Table 1, the total number of participants was 179 students, all of whom were undergraduate students of CSD at JUST. The return rate of the survey was $100 \%$. The 2nd year students had the highest mean age (21.9 years, SD 1.9) with the widest age range (18.51-30.41 years). The overall sex ratio male to female was $10 \%$. The participants' relative income rating was 8 , which is higher than the POSHA-S database median value of 0 , or exactly neutral on the -100 to +100 scale. The overall percentage of respondents born outside Jordan was 40\%. About $2.2 \%$ of the total number of respondents replied being married. Of the total sample, 4 students were Christians, 5 did not answer, and the rest were Muslims. In general, 87\% responded they spoke more than one language. None of the respondents identified themselves as a person who stutters or is mentally ill. Around $2.8 \%$ identified themselves as obese, $5.03 \%$ as left-handed, and $29.61 \%$ as intelli- 
Table 1. Demographic data for the study sample $(\mathrm{N}=179)$

\begin{tabular}{|c|c|c|c|c|c|}
\hline & Avg. & 1st year $(\mathrm{N}=46)$ & $2 n d$ year $(\mathrm{N}=47)$ & 3rd year $(N=47)$ & 4 th year $(\mathrm{N}=39)$ \\
\hline Age (yr) & $20.9(17.7-30.41)$ & $19.2 \pm 1.99(17.7-30.1)$ & $21.9 \pm 1.9(18.51-30.41)$ & $20.7 \pm .9(18.8-23.7)$ & $21.7 \pm .7(20.78-23.9)$ \\
\hline $\operatorname{Sex}^{\mathrm{a}}$ (\%total) & 10 & 10 & 9 & 12 & 8 \\
\hline Income (Jordanian Dinar [JD]) & 8 & 17 & 3 & 6 & 5 \\
\hline Education (yr) & 12 & 12.1 & 12.2 & 12 & 12 \\
\hline Born in Jordan (\%total) & 60 & 69 & 70 & 49 & 49 \\
\hline Married (\%total) & 2.2 & 2.2 & 2.1 & 0 & 5.1 \\
\hline \multicolumn{6}{|l|}{ Faith } \\
\hline Muslim & 170 & 45 & 45 & 45 & 35 \\
\hline Christian & 4 & 0 & 1 & 2 & 1 \\
\hline No response & 5 & 1 & 1 & 0 & 3 \\
\hline Speak more than one language (\%/total) & 87 & 87 & 89 & 81 & 92 \\
\hline \multicolumn{6}{|l|}{ Self-identification (\%/total) } \\
\hline Stuttering & & 0 & 0 & 0 & 0 \\
\hline Mentally ill & & 0 & 0 & 0 & 0 \\
\hline Obese & 2.79 & 2.17 & 0 & 2.13 & 7.69 \\
\hline Left handed & 5.03 & 6.52 & 4.26 & 8.51 & 0 \\
\hline Intelligent & 29.61 & 26.09 & 31.91 & 27.97 & 30.77 \\
\hline \multicolumn{6}{|c|}{ Self-rating of health and abilities (-100 to 100) } \\
\hline Physical health ${ }^{b}$ & 39 & 41 & 35 & 40 & 38 \\
\hline Mental health & 62 & 67 & 58 & 68 & 51 \\
\hline Ability to learn & 64 & 60 & 62 & 69 & 65 \\
\hline Ability to speak & 71 & 67 & 78 & 74 & 63 \\
\hline \multicolumn{6}{|l|}{ Knowledge (-100 to 100) } \\
\hline Amount known & & -23 & 5 & -13 & 47 \\
\hline Persons known & & -90 & -93 & -94 & -88 \\
\hline Personal experience & & 21 & -25 & -19 & -30 \\
\hline Time to complete POSHA-S (min) & & 10.46 & 10.6 & 10.1 & 11.5 \\
\hline
\end{tabular}

POSHA-S= Public Opinion Survey of Human Attributes-Stuttering.

aRatio of male and female.

${ }^{b}$ Number of students declined to answer: 1 in 1st year; 1 in 2nd year; 3 in 4th year; -100 negative attitude to +100 positive attitude.

gent. Overall, participants' rating of their physical health was 39, mental health 62 , ability to learn 64 , and ability to speak 71 . The mean time it took all of the participants to complete the Arabic version of the POSHA-S was 10.7 minutes. The independent two sample t-test revealed a significant difference in mean age between 1 st year and 4 th year students $(p=.00234)$.

Table 2 shows participants' ratings on the beliefs, knowledge, and reactions to stuttering and PWS. There were significant differences in the amount of knowledge about PWS between 1st and 4 th year students $(p=.000)$, between 2 nd and 4 th year $(p=.007)$, and between $3 \mathrm{rd}$ and 4 th year $(p=.000)$. The ratings on the amount of knowledge they have about people who stutter were -23 for 1st year, 5 for 2 nd year, -13 for 3 rd year, and 47 for 4 th year. Significant differences were also found on the source i.e., TV or radio, that they rely on for their information on stuttering between 1st and 4 th year students $(p=.0002)$, between 2 nd and 4 th year $(p=.002)$, and between 3 rd and 4 th year $(p=.000)$. Their ratings for TV or radio as their source of information were 22 for 1st year, 24 for 2 nd year, 13 for 3 rd year, and -67 for 4 th year. With regard to the overall rating on the source of knowledge, a significant difference was found between 3 rd and 4 th year students $(p=.0007)$. Significant differences were also found between students on the beliefs category related to the personality traits of people who stutter between 1 st and 4 th year $(p=.003)$ and 3 rd and 4 th year students $(p=.002)$. Their overall ratings on the traits items were -23 for 1st year, -24 for 2 nd year, -21 for 3 rd year, and - 38 for 4 th year students.

Moreover, there were significant differences between 1st and 4 th year students on the source a person who stutters should seek 
Table 2. Beliefs, knowledge, and reactions to stuttering and PWS of the POSHA-S database

\begin{tabular}{|c|c|c|c|c|}
\hline Subcategory & 1st year & 2nd year & 3rd year & 4th year \\
\hline \multicolumn{5}{|l|}{ Amount known } \\
\hline Stuttering ${ }^{\mathrm{a}}$ & -23 & 5 & -13 & 47 \\
\hline Source of knowledge & 13 & 19 & 32 & 0 \\
\hline TV/Radio ${ }^{\mathrm{a}}$ & 22 & 24 & 13 & -67 \\
\hline Print & 10 & 7 & 15 & 5 \\
\hline Internet & 40 & 30 & 79 & 37 \\
\hline School & -5 & -24 & -19 & -51 \\
\hline Specialists & -2 & 59 & 70 & 74 \\
\hline Traits & -23 & -24 & -21 & -38 \\
\hline Blame themselves for stuttering & 95 & 91 & 96 & 79 \\
\hline Nervous & -68 & -71 & -69 & -100 \\
\hline Shy & -95 & -91 & -91 & -95 \\
\hline Source for help & -14 & -5 & -2 & 20 \\
\hline SLP & 96 & 100 & 100 & 100 \\
\hline Stutterer & -63 & -71 & -63 & -53 \\
\hline Doctor $^{a}$ & -76 & -43 & -43 & 14 \\
\hline Cause & 4 & -2 & 8 & 8 \\
\hline Genetic $^{\mathrm{a}}$ & -10 & 3 & 73 & 71 \\
\hline Learned habit ${ }^{\mathrm{a}}$ & -5 & -35 & -7 & -68 \\
\hline Fright ${ }^{a}$ & -58 & -95 & -91 & -68 \\
\hline Act of God ${ }^{a}$ & -60 & -40 & -48 & -9 \\
\hline Virus/Disease ${ }^{\mathrm{a}}$ & 54 & 69 & 29 & 20 \\
\hline Ghost/Demons ${ }^{\mathrm{a}}$ & 100 & 85 & 91 & 100 \\
\hline Potential & 76 & 85 & 80 & 75 \\
\hline Can make friends & 100 & 96 & 96 & 95 \\
\hline Can lead normal life & 85 & 100 & 95 & 89 \\
\hline Can do any job & 90 & 82 & 77 & 78 \\
\hline Judgment job & 28 & 61 & 53 & 37 \\
\hline Helping and reactions & 48 & 49 & 49 & 40 \\
\hline Ignore & 100 & 100 & 100 & 100 \\
\hline $\mathrm{Me}$ & 3 & 11 & 41 & 53 \\
\hline Fill words & 66 & 49 & 33 & 33 \\
\hline Relax & -19 & -24 & -41 & -78 \\
\hline Joke about stuttering & 77 & 78 & 87 & 64 \\
\hline Hide their stuttering & 62 & 80 & 72 & 68 \\
\hline Distance/Sympathy & 60 & 61 & 42 & 54 \\
\hline Comfortable & 95 & 87 & 75 & 83 \\
\hline Pity & -2 & 9 & -30 & -20 \\
\hline Impatient & 86 & 86 & 81 & 100 \\
\hline
\end{tabular}

PWS = people who stutter; POSHA-S = Public Opinion Survey of Human AttributesStuttering; $S L P=$ speech-language pathologist.

aSignificant differences were observed between groups $p \leq .05$.

help from (i.e., a medical doctor) $(p=.0002)$; group scores on this item were -76 for 1st year, -43 for 2 nd and 3rd years, and 14 for 4 th year. Furthermore, there were significant differences between 1st and 4 th year on the overal items of the source of help $(p=0024)$.
Their overall ratings on this category were -14 for 1 st year, -5 for 2nd year, -2 for $3 r d$ year, and 20 for 4 th year. In addition the two sample $t$-test showed significant differences between 1st and 3rd year ( $p=.0001)$, 1st and 4 th year $(p=.00047)$, and 2 nd and 3 rd year $(p=.0004)$ on a genetic cause of stuttering. 1st year students' rating on the genetic cause was $-10,2$ nd year 3 , 3rd year 73 , and 4 th year 71 . There were also significant differences between 1st and 4 th year $(p=.0008)$, 3rd and 4 th year $(p=.002)$ in regards to whether the cause of stuttering is a learned habit; 1st year students' rating on the cause of stuttering as a learned habit was -5 , 2nd year -35 , 3rd year -7 , and 4 th year was -68 . There were significant differences between 1st and 2nd year $(p=.005)$ and 3 rd year $(p=.008)$ and there were significant differences between 4 th and 2 nd year $(p=.017)$ and 3 rd year $(p=.03)$ on the cause of stuttering being a frightining event. The scores were -58, -95, -91, and -68 for 1st, 2nd, 3 rd and 4 th year respectively. Moreover, there were significant differences between 1st and 4th year $(p=.015)$ and 3 rd and 4 th year $(p=.028)$ on the cause of stuttering being an act of God. The ratings were $-60,-40,-48$, and -9 for 1 st, 2 nd, 3 rd, and 4 th years respectively. There were also significant differecnes on the cause of stuttering being explained by a virus or disease between 2 nd and 3 rd year $(p=.037)$ and 2 nd and 4 th year $(p=.033)$. The scores were $54,69,29$ and 20 for 1st, 2nd, 3rd, and 4th years respectively. In addition, there were significant differences between 1st and 2nd year $(p=.025)$ and 2 nd and 4 th year $(p=.032)$ on the cause of stuttering being due to ghosts or demons. The scores were 100, 85, 91, and 100 for 1st, 2nd, 3rd, and 4th years respectively.

Morover, the overall data was compared to 143 samples, amounting to 11,483 respondents, on the POSHA-S database and revealed that $30 \%$ of the respondents fell within the 1st quartile range (025th percentile), $48.33 \%$ scored within the interquartile range (2575 th perecntile), and $21.67 \%$ were within the 4 th quartile range (75-100th percentile). The overall stuttering rating for the four groups was 12 and each group overall rating was 11 for 1st year, 12 for 2 nd year, 13 for 3 rd year, and 11 for 4 th year with no significant differences among the four groups. Figure 1 shows 1st to 4 th year student ratings and sub-ratings on the POSHA-S. The lowest rating on the POSHA-S database was -15 and the highest was 65 with the median 17. 


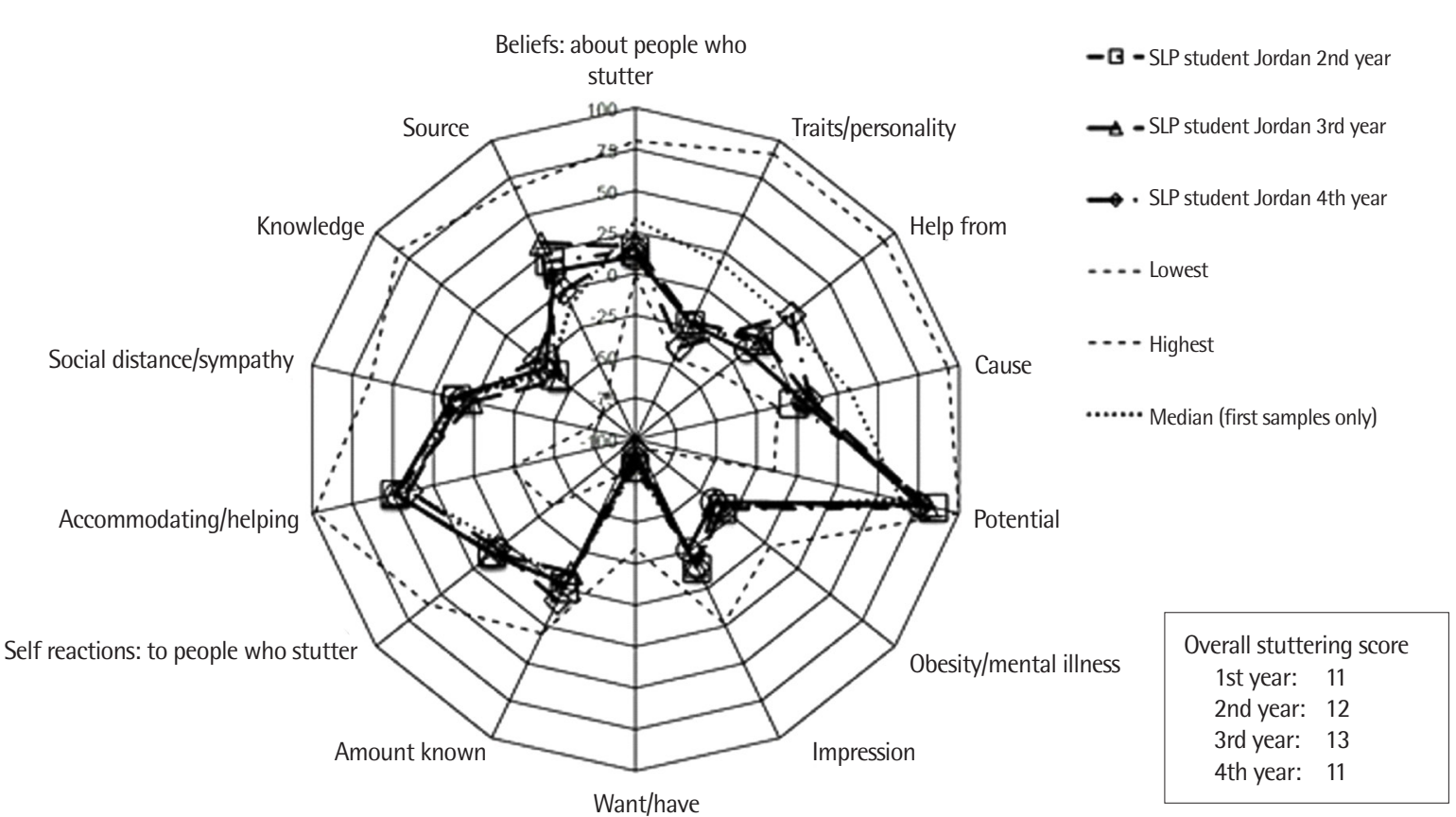

Figure 1. POSHA summary for 1 st to 4 th year undergraduate Communication Sciences and Disorders (CSD) students at Jordan University of Science and Technology. It shows the lowest, highest, and median ratings on the POSHA-S (Public Opinion Survey of Human Attributes-Stuttering).

\section{CONCLUSION}

\section{Sample Characteristics}

The total number of the sample size in the current study was 179 respondents overall. There were four groups of students sampled in this study and their numbers ranged from 39 to 47 respondents. The small number of the sub-samples that were recruited and analyzed on the POSHA-S might raise some concerns related to their accuracy of predicting the mean of the overall population attitudes. St. Louis (2008) examined this issue with sample sizes of $12,25,50,100$, and 200 subjects using convenience and random samples; he concluded that sample sizes ranging between 25-50 respondents provide accurate means using the POSHA-S. Moreover, the current study showed an imbalance in gender representativeness; however the profession of speech language pathology is female dominated and this creates an imbalance in studies that target speech pathologists (Koutsodimitropoulos et al., 2016). Such imbalance did not allow for within group comparisons based on gender in the current study. It is worth mentioning that the percentages of males in the current study were $8 \%, 9 \%, 10 \%$, and $12 \%$ for 1 st to 4 th year students respectively. Although gender differences in attitude among Arabs have been reported in studies of other disorders, such as voice disorders; Irani, Abdalla, \& Hughes (2014) found less social acceptance and fewer positive attitudes in male adults toward people with voice disorders when compared to their female counterparts. Nonetheless, Abdalla and St. Louis (2014) found that male and female in-service teacher controls in their study held the same negative attitudes toward stuttering and PWS compared to pre-service teachers.

\section{Participants' Ratings Compared to Participants on the POSHA-S}

Ratings of the participants of this study are low compared to the ratings on the POSHA-S database as the median on the POSHA-S is 17 and the overall stuttering rating of the subjects of the current investigation falls below the median. Nonetheless, the overall stuttering ratings in the current study are a little higher than the ratings of both a Jordanian (Alshdifat et al., 2013) and Turkish (Özdemir et al., 2011a, 2011b) study of the general public attitude, but a little lower than a Saudi study on the general public attitude in 
the Eastern Province (F. Abdullah, personal communication, January 8,2014$)$. The higher rating of the current study sample compared to an Alshdifat et al. (2013) study might be attributed to two reasons: First, the participants in the current study were undergraduate students in CSD and this might have influenced their ratings to some extent supporting the positive 'halo effect' conclusion of St. Louis, Przepiorka, et al. (2014) of students being in a CSD program. It seems that this effect is seen across the 4 groups in this study as 1 st and 2 nd year students do not have any contact with PWS and 3rd year students have minimal contact since they have already started their fluency clinical training courses. Second, participants in the Alshdifat et al. (2013) study came from one city whereas participants in the current study came from different backgrounds and this might have positively affected the ratings. Nonetheless, most of the students who reported being born outside Jordan are born to Jordanian parents who work abroad. Although there were no differences seen among the four groups on the overall rating of their attitudes toward stuttering and people who stutter, 4th year students demonstrated significant differences from 1st year students on the source of help. This might be attributed to having taken a course in fluency disorders.

The majority of participants in the current study viewed PWS as shy and nervous. This finding is in agreement with other studies from the Middle East (Abdalla \& St. Louis, 2012, 2014; Al-Khaledi et al., 2009; Alshdifat et al., 2013; Elsiddig et al., 2013; F. Abdullah, personal communication, January 8, 2014; Özdemir et al., 2011b). Furthermore, a helping strategy they advocate for PWS is telling them to "Slow down" or "Relax"; the 4th year students were the lowest on this item (i.e., -78). On the other hand, the majority of respondents in the current study believed that PWS are not to blame themselves for their stuttering disorder which is also in agreement with the same previous studies from the same region. As can be seen from the ratings of the four groups in Table 1, most of the participants had never had experiences with PWS which means they have neither encountered nor had long contact with PWS. Even though this might partially explain the low ratings of 1 st to $3 \mathrm{rd}$ year students on the POSHA-S, it does not explain why 4 th year students had similar ratings to 1st to 3rd year students. Even though 4 th year students participating in the current study had taken a course in fluency disorders in the second semester of their 3rd year, it is possible that they might have not had sufficient encounters with people who stutter in their training to result in more positive ratings. People who have had contact with PWS for long periods of time are more likely to hold more positive attitudes toward them (Irani et al., 2012), which means that change in attitude might be slow, requiring years. Irani et al. (2012) reported that teachers' attitudes toward PWS in the US shifted positively over a period of two decades. Thus, negative stuttering stereotypes may require more than just a course in fluency disorders or being in a CSD program to diminish as these internalized negative stereotypes that may have set in for years. Future research on students and SLPs from the same region might want to compare the attitudes of SLPs who have been practicing fluency therapy for some time beyond their graduation and compare them to the attitudes of undergraduate SLP students.

It is well documented that school teachers have great influence on students (Abdalla \& St. Louis, 2012). Irani et al. (2012) refer to school teachers as 'authority figures'. When teachers were asked to explain why they did not recommend certain jobs for persons who stutter, they responded that they had the 'best interest of their students who stutter in mind (Irani, Gabel, Hughes, Swartz, \& Palasik, 2009). Even though this might explain some of the negative attitudes people might have toward people who stutter, this does not apply to our sample of students of CSD as they felt that PWS have positive potential. This might also mean that attitudes do change as a result of being in a CSD program, although only partially. For example, St. Louis, Przepiorka, et al. (2014) reported that graduate SLP students had more positive attitudes toward PWS than undergraduate SLP students in the USA.

With regard to the cause of stuttering, the four groups had variably low ratings on learning and frightful event as causes of stuttering despite the fact that $3 \mathrm{rd}$ and 4 th year students had positive high ratings on the genetic cause of stuttering. Half of the CSD students in St. Louis and Lass (1981) believed stuttering had a psychological cause. Participants in the current study had negative ratings on the 'act of God' as a cause of stuttering. This finding is consistent across studies that examined the same faith group, namely 'Muslims', in different studies (Al-Khaledi et al., 2009; Alshdifat et al., 2013; Elsiddig et al., 2013; F. Abdullah, personal communication, January 8, 2014; Özdemir et al., 2011b). Attributing such 
finding to education level does not seem viable as the cited previous research included different groups of people with different educational levels. So, trying to provide a reasonable interpretation for this consistent finding among Muslims cannot be ignored. It is common among Muslims to attribute causes of different happenings to 'acts of God'. With this being said, it does not prevent them from looking for help for their health issues. This is apparent in the source for help they would resort to for their fluency problems; most of the respondents stated they would see an SLP for help for their stuttering problem (Al-Khaledi et al., 2009; Alshdifat et al., 2013; Elsiddig et al., 2013; F. Abdullah, personal communication, January 8, 2014; Özdemir et al., 2011b). In addition, Elsiddig et al. (2013) found that their participants rated an Imam or religious leader as the least source for help PWS should go to for assistance for their fluency problem. Moreover, none of the Arab immigrants who participated in the Nilsson and Wetterling (2013) study attributed the cause of stuttering to an 'act of God'. Perhaps because they had a better understanding of western culture, most of them answered 'I do not know'. However, only one third of the respondents thought that an SLP is the best source for help for PWS, while the rest were unsure who is best to provide help, implying insufficient knowledge of the disorder. St. Louis (2015) called for more research to help explore factors that account for differences in attitudes toward stuttering and PWS among people from different geographical locations and countries. This calls researchers to approach the 'act of God' cause of stuttering with caution when Muslims are included in such studies as it might lead to incorrect conclusions about participants' knowledge and attitudes about stuttering and PWS. Support for this notion comes from St. Louis et al. (2016) where they found their Muslim participants in BosniaHerzegovina had more positive attitudes than their Catholic and Orthodox respondents.

The distance/sympathy dimension, i.e., pity, ratings were all negative among the groups with the exception of the 2 nd year students, who had a positive low rating on this item. These ratings are similar to ratings of subjects from the same country (Alshdifat et al., 2013) and the same region (Abdalla \& St. Louis, 2012, 2014; Alkhaledi et al., 2009; Alshdifat et al., 2013; Özdemir et al., 2011b). This also calls for more research on why Arabs in general regard PWS with pity. The first two authors speculate that the reasons for this might be either cultural, religious, or both. Feeling pity for persons with disabilities is prevalent among Muslims (Hasnain, Cohon, \& Shanawani, 2008). Pity/sympathy is no doubt a negative attitude because it does not promote people to change attitudes toward PWS or people with disabilities. On the other hand, empathy promotes people's understanding of the true difficulties of PWS and thus show more positive attitude toward them (St. Louis, 2011).

Flynn and St. Louis (2011) found an oral presentation by a stutterer resulted in quick and more positive change in high school students' attitudes toward stuttering than a video presentation. This might underscore the importance of providing live demonstrations or contact with PWS in an undergraduate fluency course in the future. Pivotal to such approach is the question of whether a change in attitude can have a long term effect or a short one. The importance of follow up studies of the attitudes of people who show a change in attitude after being exposed to informative demonstrations about stuttering and PWS is significant. The goal of programs that aim at changing the attitude of people toward stuttering and PWS is to effect long term change rather than short term change. Even though there was a shift in the attitudes of school teachers in Kuwait in a positive direction toward stuttering and PWS (Abdalla \& St. Louis, 2014) after watching a video presentation on stuttering, this shift in attitude was limited to pre-service teachers who were receiving training to become school teachers after receiving pretreatment, but not for in-service school teachers. In-service school teachers have secure jobs, and therefore might reject information presented to them in a pre-treatment training and feel in a position to freely express their internalized attitudes toward stuttering and PWS more than pre-service teachers who might feel the opposite. In another vein, Gabel (2006) found that his participants viewed PWS who attended therapy more positively than those who did not. Moreover, he controlled for the long standing contact effect with PWS by excluding those who knew people who stuttered. Only descriptions were provided to the participants about each person to be judged in the study, i.e., severe vs. mild stutterer, and opted for therapy or did not; but definitions of severity and therapy were left to the participants' own definitions. Real life experience with stuttering and PWS might be different from descriptions and might have their different effects on attitudes. This indeed highlights the importance of exploring differ- 
ent people's attitudes toward stuttering and PWS in order to identify gaps in information available regarding what might influence public attitudes toward PWS and which methods are best suited to affect change in these attitudes. Future research on speech-language pathology students' attitudes might benefit from comparing more than one educational method to check which one might be quicker and effect more change in attitude. Abdalla and AlSaddah (2009) reported that one of the children who stuttered in their study was told by her teachers to ask questions after class or during break time, which was interpreted by Irani et al. (2012) as marginalization of students who stutter. While might be the case, it is possible that teachers feel that such requests are in the best interest of their students who stutter in order to protect them from other students who might stigmatize or bully them, which is believed to be a serious issue by teachers in Kuwait (Abdalla \& St. Louis, 2012). These teachers may feel that this is the best thing they can do to help students who stutter, and such actions might reflect the teachers' lack of knowledge on how to address this issue.

It is worth reiterating that attitudes toward PWS vary across cultures and geographic locations (Abdalla \& St. Louis, 2012). This might explain why SLP and non-SLP students from the USA (St. Louis, Williams, Ware, Guendouzi, \& Reichel, 2014) were found to have higher positive attitudes than Jordanian students in the current study even before they were exposed to instruction in a fluency disorders course. Generally, research suggests that people from western countries hold more positive attitudes than people from Middle Eastern countries. Even Muslims from Bosnia and Herzegovina were found to have higher positive attitudes than Muslims from Middle Eastern countries (St. Louis et al., 2016). Such variability calls for careful consideration of the factors that lead to more negative attitudes in one culture than another and in one geographic location than another.

In conclusion, participants in the current study showed positive attitudes toward stuttering and PWS in general. They did not show much positive change in their overall attitude toward stuttering and PWS as they progressed from one year to the next in their program of study. In addition, they showed lower overall attitudes compared to other samples from Middle Eastern countries. Such variability between the sample of the current study and other samples from Middle Eastern countries might be explained by geo- graphic location. CSD students from western countries hold higher positive attitudes toward stuttering and PWS even prior to their enrollment in a fluency disorder course; this difference is interpreted as a result of differences in culture and geographic location as the public in such countries hold more positive attitudes than people from the Middle East. Different educational methods might need to be added to instruction to affect quicker positive change in attitude of students who are in a CSD program.

The current study undoubtedly had limitations. First, this study was limited to undergraduate CSD students in one university in Jordan. Future studies might need to consider including students from other majors and from other schools in Jordan to allow for more informed comparisons and conclusions. Second, the current study included neither graduate CSD students nor practicing SLPs to allow for measuring attitude change in clinicians' attitudes toward stuttering and PWS as a function of long contact. Not including undergraduate and graduate CSD students, students form other majors and other schools, and practicing SLPs was due to limited resources and limited accessibility to these populations within a small window of time. Future studies might consider exploring attitudes of graduate and practicing SLPs toward stuttering and PWS. The sample size for each of the four groups was sufficient to allow for between group comparisons, but each group size was insufficient to allow for within-group comparisons based on sex, age, birth place and upbringing since a good deal of the students in each group came from a different country. Future studies might include larger sample sizes of students from different schools in Jordan to allow for such analysis and comparisons.

\section{REFERENCES}

Abdalla, F., \& Al-Saddah, A. (2009). Stuttering and teachers in Kuwait: the story so far. https://www.mnsu.edu/comdis/isad12/papers/abdalla12.html. Abdalla, F., \& St. Louis, K. O. (2012). Arab school teachers' knowledge, beliefs and reactions regarding stuttering. Journal of Fluency Disorders, 37, 54-69.

Abdalla, F., \& St. Louis, K. O. (2014). Modifying attitudes of Arab school teachers toward stuttering. Language, Speech, and Hearing Services in Schools, $45,14-25$.

Al-Khaledi, M., Lincoln, M., McCabe, P., Packman, A., \& Alshatti, T. (2009). 
The attitudes, knowledge and beliefs of Arab parents in Kuwait about stuttering. Journal of Fluency Disorders, 34, 44-59.

Alshdifat, K., Mayo, R., \& St. Louis, K. (2013). Attitudes of Jordanians toward stuttering and people who stutter. Paper presented at the Annual Convention of the American Speech-Language-Hearing Association, Chicago, IL.

Bellegarde, M., Mayo, R., St. Louis, K. O., \& Mayo, C. M. (2016). Public opinions of stuttering in Haiti. ECHO: Journal of the National Black Association for Speech-Language and Hearing, 11, 35-44.

Dhingra, Y., \& Bhnatnagar, V. (2006). Attitudes of speech-language pathology students toward persons with disability. Asia Pacific Rehabilitation Journal, 17, 94-99.

Elsiddig, Y., Haynes, C., Atwood, J., \& St. Louis, K. (2013). Exploring the Sudanese stuttering experience: perceptions, attitudes, \& locus of control. Poster presented at the Annual Convention of the American Speech-LanguageHearing Association, Chicago, IL.

Flynn, T. W., \& St. Louis, K. O. (2011). Changing adolescent attitudes toward stuttering. Journal of Fluency Disorders, 36, 110-121.

Gabel, R. M. (2006). Effects of stuttering severity and therapy involvement on attitudes towards people who stutter. Journal of Fluency Disorders, 31, 216-227.

Ham, R. E. (1990). What is stuttering: variations and stereotypes. Journal of Fluency Disorders, 15, 259-273.

Hasnain, R., Shaikh, L. C., \& Shanawani, H. (2008). Disability and the Muslim perspective: an introduction for rehabilitation and health care providers. Buffalo, NY: Center for International Rehabilitation Research Information and Exchange.

Ip, M. L., St. Louis, K. O., Myers, F. L., \& Xue, S. A. (2012). Stuttering attitudes in Hong Kong and adjacent Mainland China. International Journal of SpeechLanguage Pathology, 14, 543-556.

Irani, F., Abdalla, F., \& Gabel, R. (2012). Arab and American teachers' attitudes toward people who stutter: a comparative study. Contemporary Issues in Communication Science and Disorders, 39, 12-20.

Irani, F., Abdalla, F., \& Hughes, S. (2014). Perceptions of voice disorders: a survey of Arab adults. Logopedics Phoniatrics Vocology, 39, 87-97.

Irani, F., Gabel, R., Hughes, S., Swartz, E. R., \& Palasik, S. T. (2009). Role entrapment of people who stutter reported by K-12 teachers. Contemporary Issues in Communication Science and Disorders, 36, 45-54.

Koutsodimitropoulos, E., Buultjens, M., Louis, K. O. S., \& Monfries, M. (2016). Speech pathology student clinician attitudes and beliefs towards people who stutter: a mixed-method pilot study. Journal of Fluency Disorders, 47,
38-55.

Mallah, L. (2011). A comparison of the attitudes, knowledge and beliefs about stuttering in British university students living in the United Kingdom (UK) and Syrian university students living in Syria (Master's thesis). University of Reading, Reading, UK.

Maviş, İ., Louis, K. O. S., Özdemir, S., \& Toğram, B. (2013). Attitudes of Turkish speech and language therapists toward stuttering. Journal of Fluency Disorders, 38, 157-170.

Nilsson, S., \& Wetterling, T. (2013). "Try to relax": a survey study in Sweden among native Swedes and Arabic immigrants concerning views on stuttering (Master's thesis). Lund, Sweden: Lund University.

Özdemir, R. S., St. Louis, K. O., \& Topbaş, S. (2011a). Public attitudes toward stuttering in Turkey: probability versus convenience sampling. Journal of Fluency Disorders, 36, 262-267.

Özdemir, R. S., St. Louis, K. O., \& Topbaş, S. (2011b). Stuttering attitudes among Turkish family generations and neighbors from representative samples. Journal of Fluency Disorders, 36, 318-333.

Reichel, I., \& St Louis, K. O. (2004). The effects of emotional intelligence training in fluency disorders classes. In H. G. Bosshardt et al. (Eds.), Fluency disorders: theory, research, treatment, and self-help (pp. 474-481). Nijmegen, The Netherlands: Nijmegen University Press.

Reichel, I., \& St Louis, K. O. (2007). Mitigating negative stereotyping of stuttering in a fluency disorders class. In J. Au-Yeung \& M. M. Leahy (Eds.), Research, treatment, and self-help in fluency disorders: new horizons (pp. 236-243). Dublin, Ireland: International Fluency Association.

Ruscello, D. M., Lass, N. J., French, R. S., \& Channel, M. D. (1989). Speechlanguage pathologists' perceptions of stutterers. National Student Speech Language Hearing Association Journal, 17, 86-89.

St. Louis, K. O. (2008). Surveying public attitudes toward stuttering: considerations of sample size. Paper presented in the Annual Convention of the Speech-Language-Hearing Association. Chicago, IL.

St. Louis, K. O. (2011). The Public Opinion Survey of Human Attributes-Stuttering (POSHA-S): summary framework and empirical comparisons. Journal of Fluency Disorders, 36, 256-261.

St. Louis, K. O. (2012). Research and development on a public attitude instrument for stuttering. Journal of Communication Disorders, 45, 129-146.

St. Louis, K. O. (2015). Epidemiology of public attitudes toward stuttering. In K. O. St. Louis (Ed.), Stuttering meets stereotype, stigma, and discrimination: an overview of attitude research (pp. 7-42). Morgantown, WV: West Virginia University Press. 
St. Louis, K. O., Abdalla, F., Burgess, M. E., \& Kuhn, C. D. (2013). Public attitudes toward mild versus severe stuttering in the USA and Kuwait. Poster presented at the Stuttering Attitudes Research Symposium, Morgantown, WV.

St. Louis, K. O., Andrade, C. R., Georgieva, D., \& Troudt, F. O. (2005). Experience and personal report about an international cooperation research, Brazil, Bulgaria and Turkey: attitudes toward stuttering. Pró-Fono Revista de Atualização Cientifica, 17, 413-416.

St. Louis, K. O., \& Lass, N. J. (1981). A survey of communicative disorders students' attitudes toward stuttering. Journal of Fluency Disorders, 6, 49-79.

St. Louis, K. O., Przepiorka, A. M., Beste-Guldborg, A., Williams, M. J., Blachnio, A., Guendouzi, J., ... \& Ware, M. B. (2014). Stuttering attitudes of students: Professional, intracultural, and international comparisons. Journal of Fluency Disorders, 39, 34-50.

St. Louis, K. O., \& Roberts, P. M. (2010). Measuring attitudes toward stuttering: English-to-French translations in Canada and Cameroon. Journal of Communication Disorders, 43, 361-377.

St. Louis, K. O., Sønsterud, H., Junuzović-Žunić, L., Tomaiuoli, D., Del Gado,
F., Caparelli, E., ... \& Kvenseth, H. (2016). Public attitudes toward stuttering in Europe: within-country and between-country comparisons. Journal of Communication Disorders, 62, 115-130.

St. Louis, K. O., Williams, M. J., Ware, M. B., Guendouzi, J., \& Reichel, I. K. (2014). The Public Opinion Survey of Human Attributes-Stuttering (POSHA-S) and Bipolar Adjective Scale (BAS): aspects of validity. Journal of Communication Disorders, 50, 36-50.

Turnbaugh, K. R., Guitar, B. E., \& Hoffman, P. R. (1979). Speech clinicians' attribution of personality traits as a function of stuttering severity. Journal of Speech, Language, and Hearing Research, 22, 37-45.

Van Borsel, J., Verniers, I., \& Bouvry, S. (1999). Public awareness of stuttering. Folia Phoniatrica et Logopaedica, 51, 124-132.

Woods, C. L., \& Williams, D. E. (1976). Traits attributed to stuttering and normally fluent males. Journal of Speech and Hearing Research, 19, 267278.

Yairi, E., \& Williams, D. E. (1970). Speech clinician's stereotypes of elementary-school boys who stutter. Journal of Communication Disorders, 3, 161170. 


\section{국문초록}

\section{요르단과학기술대학교 의사소통장애 전공 학생의 말더듬 및 말더듬는 사람에 대한 태도 연구}

Khalid G. Al-Shdifat'(교수, 제1저자, 교신저자) · Mikhled Maayah'(교수) · Robert Mayo²(교수) · Kenneth St. Louis ${ }^{3}$ 교수)

${ }^{1}$ 요르단과학기술대학교, ${ }^{2}$ 노스캐롤라이나 그린즈버러 대학교, ${ }^{3}$ 웨스트버지니아 대학교

배경 및 목적: 본 연구는 요르단과학기술대학교(JUST)에서 의사소통장애(CSD)를 전공하는 1-4학년 학생들을 대상으로, 이들의 말 더듬 및 말더듬는 사람(PWS)에 대한 태도를 살펴보았다. 방법: JUST에서 CSD를 전공하는 1-4학년 학생들이 본 연구에 참여하였다. 표준화 검사도구인 POSHA-S의 아랍어판을 이용하여 각 학년의 말더듬 태도를 비교하였고, POSHA-S 데이터베이스를 다른 나라의 $\mathrm{CSD}$ 전공학생 집단 및 일반 집단과 비교분석하였다. 결과: JUST의 CSD 전공학생을 대상으로 데이터를 수집한 결과 학년의 증가가 말 더듬에 대한 전반적 태도의 유의한 변화를 가져오지는 않았다. 그러나 요르단의 일반 집단보다는 더 긍정적인 태도를 보인 것으로 나타 났다. POSHA-S 데이터베이스와 비교해 보았을 때, 요르단 학생들의 태도는 다른 국가에서 표집된 대부분의 SLP 학생들보다 덜 긍정적 이었다. 논의 및 결론: 본 연구 결과에 따르면 요르단의 CSD 전공학생들은 다른 국가의 CSD 전공학생 집단과 비교하여 말더듬 및 말 더듬는 사람에 대한 태도가 덜 긍정적인 것으로 나타났다. 이 결과를 말더듬 및 말더듬는 사람에 대한 태도를 연구한 관련문헌들과 비 교, 논의하였다.

핵심어: 말더듬, 태도, CSD 전공학생, POSHA-S, 아랍어 